\title{
Moderate reductions in animal protein intake could substantially decrease pressure on environment when food system change is optimised
}

Mika Jalava ( $\sim$ mika.jalava@aalto.fi )

Aalto University https://orcid.org/0000-0003-4133-7462

Joseph Guillaume

Australian National University

Matti Kummu

Aalto University https://orcid.org/0000-0001-5096-0163

Vera Heck

Potsdam Institute for Climate Impact Research

Olli Varis

Aalto University, Espoo, Finland

Article

Keywords:

Posted Date: January 20th, 2022

DOI: https://doi.org/10.21203/rs.3.rs-1258536/v1

License: (9) This work is licensed under a Creative Commons Attribution 4.0 International License.

Read Full License 

substantially decrease pressure on environment when food system change is optimised

Authors: Mika Jalava ${ }^{1}$, Joseph H.A. Guillaume ${ }^{1,2}$, Matti Kummu' ${ }^{1}$, Vera Heck ${ }^{1,3}$, Olli Varis ${ }^{1}$

Affiliations: $\quad$ 1. Water \& Development Research Group, Aalto University, Espoo, Finland

2. Institute for Water Futures and Fenner School of Environment \& Society, Australian National University, Canberra, Australia

3. Potsdam Institute for Climate Impact Research, Potsdam, Germany

\section{Abstract}

Diet change towards less animal protein is often proposed as one of the key opportunities to produce more food with less natural resources. However, depending on how feed is provided, part of the livestock production could be sustainable - but how large a part remains to be answered. The key challenge has been that the existing methods assessing the impacts of altering the level of animal protein in diets rely on static use of resources, and do not take into account the changes needed in entire food system; including the use of by-products for feed, how efficiently the replacing plantbased protein could be produced with land freed from feed production or pasture, etc. We developed an integrated global food system model "Aalto OptoFood" that allows us to assess dynamically the response of these scenarios on different parts of the food system, and thus optimise the diet transition from the point of view of resource use. We show that even moderate decrease in animal protein consumption can yield a substantial reduction in, here, water consumption. Reductions of one-fifth in livestock protein would decrease water consumption by $24-26 \%$; $60-79 \%$ of total reduction potential and 3-5 times more than an estimate using the existing static methods. Water consumption levels off after $40-50 \%$ cut in animal protein intake, indicating that part of the meat consumption may be sustainable from a water perspective. These results are driven by dynamics between food production sectors and show the importance of non-food animal feeds, highlighting the need to use an integrated systemic approach in food system studies.

Main

The growth of the human population, increasing affluence and food trade, together with aspirations towards adequate, healthy diets are placing increasing demands on food production and distribution systems ${ }^{1}$. Land, water and nutrients are critical agricultural resources, and their increasing use would have detrimental effects on ecosystems and competing human demands ${ }^{2}$. Many production and demand side measures exist for mitigating the pressures imposed by food production ${ }^{3,4}$. Yield gap closure $^{5,6}$ and cropland reallocation ${ }^{7,8}$ aim to improve food production efficiency, reducing resource use per unit output. Demand-side measures curtail the food production needed to meet human nutritional needs, by cutting food losses and waste ${ }^{9,10}$ and overconsumption ${ }^{11}$, or shifting demand towards equivalent products that require less resources ${ }^{12-14}$. 
A commonly discussed demand-side approach involves shifting towards more resource efficient, plantbased diets, while maintaining (or optimizing) caloric and protein intake, together with other nutrition guidelines ${ }^{12,15,16}$. From a resource use perspective, the livestock sector is inefficient and replacing livestock products with vegetal products could free up land, water, and other resources for other human uses and ecosystems ${ }^{3,17-19}$. Nevertheless, animals are an integral part of the food system that can enhance food security: livestock is able to convert non-food crops, food co-products and substandard quality food crops into human edible food. For example, Davis and $D^{\prime}$ Odorico ${ }^{20}$ estimated that $56 \%$ of animal calories in human diet do not compete with crop use. Similarly, Mottet et al. ${ }^{21}$ and Sandström et $\mathrm{al}^{22}$ stated that $86 \%$ and $89 \%$, respectively, of the current livestock feed intake is not edible by humans. However, also the consumption of roughage from pastures - which does not directly compete with human diet - may increase the pressure on local ecosystems ${ }^{23,24}$.

Footprint methodologies ${ }^{25}$ are in common use for evaluating the natural resource impacts of animal protein intake change (hereafter diet change). Their advantage is in providing resource consumption estimates for final products through their supply chains, allowing comparison of footprints of livestock products and their alternatives. However, footprint estimates are location specific, and depend on farming practices at the time of assessment. When dealing with (substantial) production changes, it is very likely that products' footprints would change too, as the production might need to be relocated to new areas where the crop in question is not currently grown. Although comprehension of the global food system has evolved greatly ${ }^{26,27}$, it remains difficult to predict how production would change spatially in response to large shifts in food demand, even if dynamic land use models such as MAgPIE have made progress in representing assumptions about gradual decreases in livestock consumption and gradual change in technologies and costs ${ }^{28}$.

Our main aim is to explore how the gradual reduction of animal protein intake would impact on resources use, here water, and whether we can find some evidence of sustainable share of animal protein intake from a resources point of view. Our study advances the field in three ways. First, with our dynamic global food system model Aalto OptoFood (see Methods; Figure 1), developed here, we were able to estimate the changes in resources use due to potential re-allocation of croplands resulting from diet changes. When animal protein intake is reduced, the replacing plant-based protein production needs to be increased. Existing studies utilising footprint-based or otherwise fixed resource and impact assessments $^{29}$ have assumed that these additional yields can be grown with similar resources use to those of the currently grown crops, although this is often not the case $\mathrm{e}^{30}$. Therefore, our method produces more reliable estimates of how the resources in entire food system would change with changing diet.

Second, our optimisation algorithm allows us to determine where land could be most efficiently converted from animal feed production to plant-based protein production. Existing research on these interactions is detailed but local and case-specific ${ }^{31,32}$, and thus might produce too conservative estimates for the potential of diet change on resources use. The optimisation algorithm also allowed us to explore the different target functions; for example, whether to minimise overall resources use or use of resources in most stressed areas. Third, we incorporate dynamically the different parts of the food system to our Aalto OptoFood model, including the by-product use for animal feed, pastures, and crop production for both human food and animal feed. With this we can assess the trade-offs between crops and various sources of feed as well as consider the flow-on effects of changing demand for where crops are grown and alternative uses of livestock feed. Changes in one sector are reflected in others following 
the use of different fractions of the same product. This allows capturing resource efficiency throughout the whole food system, unlike comparing crop and livestock sectors as separate entities ${ }^{33}$.

Our Aalto OptoFood global food system model, developed here, is based on three different modules (see Methods; Figure 1), which combine agricultural land use, optimisation of land use with linear programming and then the global food system module that manages the flows between different sectors and adjusts food losses as well as potential diet change scenarios. The model allows us to analyse spatial variability in the evapotranspiration (proxy to water resources use) and crop yield data to reveal the potential impacts of diet change scenarios and impounded uncertainties, depending on where crops are grown. Gradually replacing animal protein with plant-based protein sources, in this example pulses (including e.g. lentils, beans and peas; see Methods) and soy, illustrates the processes driving the effect of diet change and for the first time shows how water use and its impacts decrease in response to diet change when the dynamics of the entire food system are taken into account. We explore the impacts in terms of three different optimisation objectives: minimising either evapotranspiration (MinET), water stress (MinStress) or absolute difference from natural evapotranspiration (MinDiff) (Fig 1). With the model we are able to provide more thorough estimates of the sustainable levels of livestock production. Further, the method can readily be adapted to more detailed diet change scenarios or other changes in the demand of foodstuffs.

97

98
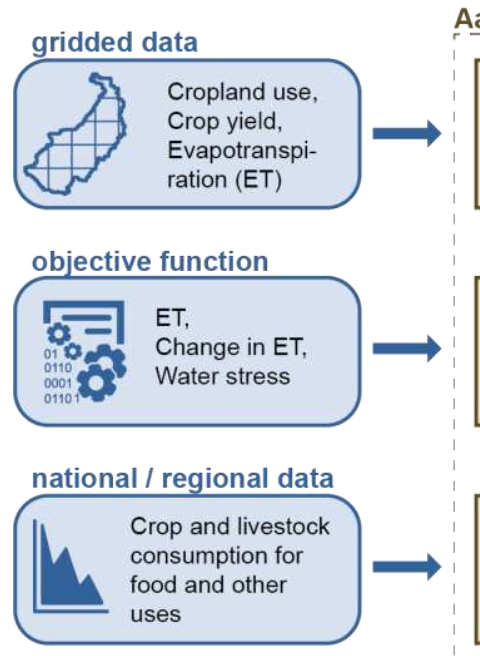

Aalto OptoFood_-model
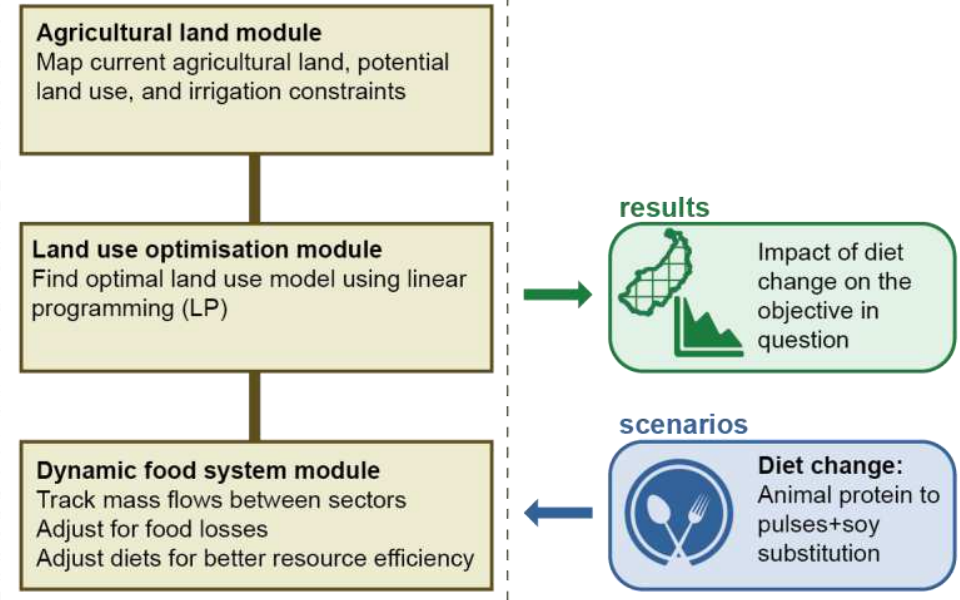

Figure 1: Conceptual structure of the Aalto OptoFood model

\section{Results}

\section{Impact of crop production location on evapotranspiration}

The spatial heterogeneity in production conditions and crop yields is the primary driver of locally varying water consumption (i.e. evapotranspiration) of each crop, essential to consider when production patterns shift with diet change ${ }^{8}$. These stem from factors such as soil, climate, and terrain. They lead to changes in water productivity when crop production is reallocated. If we look at large changes in production (like the diet change levels considered here), we do not know where the new production of 
protein rich plant products would occur. Therefore, there is substantial uncertainty in the total water requirements of the new diet. This uncertainty is quantified here using the 'Agricultural land module' of OptoFood (see Figure 1; Methods), as illustrated for pulses in Figure 2 showing the range of possible total evapotranspiration as a function of production.

112 The current land use pattern corresponds to a single modelled or estimated total evapotranspiration 113 ('current production' vertical line in Figure 2a). To map the uncertainty, we then assumed that a) the existing land use is maintained when increasing production, and $b$ ) decreases in production occur by only reducing existing cropland ("land use stickiness constraints", see Method). We evaluated the envelope of change in ET of pulses respecting these constraints visualized here for the first time as a characteristic "butterfly diagram" (Figure 2a), where increases in production always yield increases in evapotranspiration (dashed lines), and vice versa for decreases (solid lines). As production reduces, the minimum ET occurs when the least efficient land in terms of water productivity is displaced first. The maximum ET, in turn, occurs as the most efficient land is displaced first (see Figure 2). Similarly, as production increases, the minimum ET occurs when the most efficient land from the available pool is used first, and maximum ET when the least efficient land is utilised first. Practical changes in evapotranspiration in response to production shifts fall between these extreme scenarios.

However, the shape of the envelope would be very different with free allocation of all cropland to any crop (Figure 2b). With no production, consumptive water use is zero, and when all suitable cropland is used (outside the limits of the $x$-axis of the graph), the total evapotranspiration is also known. In between, the vertical distance between the curves represents the uncertainty in the water use at each level of total production caused by not knowing where production will occur.
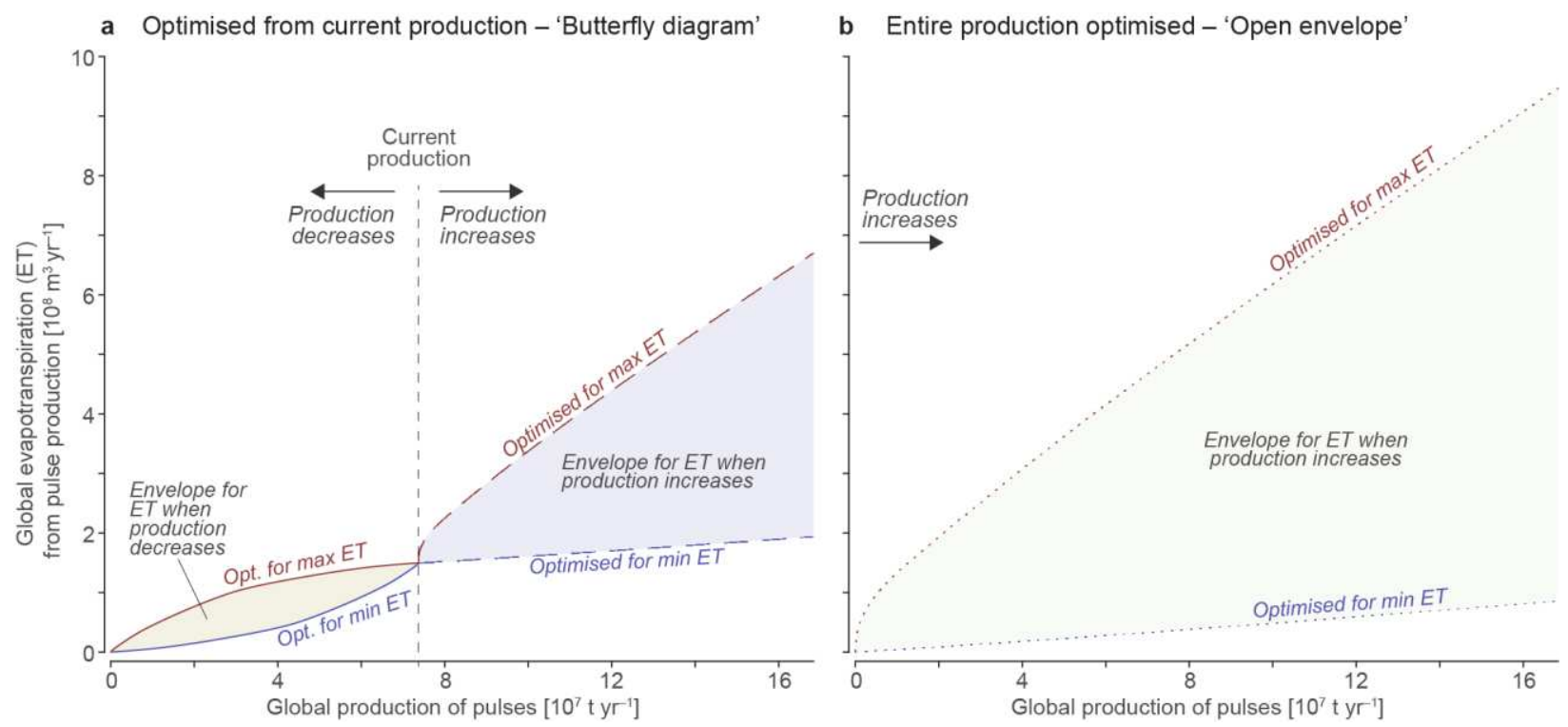

Figure 2: Range of possible evapotranspiration in response to changes in production of pulses. a) Existing land use is maintained when increasing production, while decreases in production occur by reducing existing cropland. b) Production can be redistributed through all available arable land. The vertical distance between the lowest and highest ET for a given amount produced represents the uncertainty in ET due to not knowing where pulses will be produced.

134 Within the bounds of the "butterfly diagram" (Figure 2a), the 'Land use optimisation module' of OptoFood then selects the crop areas that optimise water use or its impacts. It is important to note that 
this is not the same as following the lower curve in that diagram. The same land may be optimal for several crops, such that the optimisation needs to manage the trade-offs between them. The land freed by crops with decreasing livestock production (i.e. the cropland used for animal feed) and used by crops with increasing production depends on the properties of all the crops and changes in their demand.

A similar principle applies to livestock products. While the water requirements to produce a kilogram of a certain crop are roughly determined by the production location, however, many paths can lead to similar livestock products having very different water footprints. Livestock production can to some extent adjust to available feed supplies ${ }^{34,35}$. We also apply "stickiness" constraints to livestock production systems, such that no livestock product or production system can increase production as a result of the diet change, i.e. no production can be moved from one area or system to another.

\section{How can livestock make a positive contribution to food supply?}

Estimates of the diet-water use relationship depend on how livestock feed is represented, as summarised in Table 1. Livestock can be considered to contribute positively to human food supply when providing an efficient use of resources, in particular, when the feed required for the animals does not have any better use (human or other), i.e. the food supply resulting from the livestock sector is greater than could otherwise be obtained from the same resources. As we only modelled food system dynamics, additional non-food uses above the current level were not included in our scenarios, although in practice they may be an important consideration.

Consistent with previous work ${ }^{20,36}$, a portion of non-arable rangelands is considered "free" - meaning that not all non-irrigated grass is counted in water use. That is, those areas consume water through evapotranspiration, but that consumption does not need to be reduced as it is not usable for other food production ${ }^{20,36}$ and the evapotranspiration is close to that of natural vegetation. This specifically applies to the subset of rangelands where grazing at a sustainable intensity is beneficial for biodiversity and ecosystem functioning ${ }^{37-39}$ and where cropping is not only non-economical, but also represents a substantial departure from a natural environment ${ }^{40}$.

With our 'Dynamic food system module' of the OptoFood (Figure 1; Methods), we were also able to redirect unused feed production resources, due to diet change, into other food products - unlike existing footprint-based methods. It should be noted, that we do not consider the potential to redirect feed production into, for example, biofuels, which also has co-production dynamics with livestock ${ }^{41}$, or improvement of biodiversity, which is only represented in our results by reduction in human water and land use.

Figure 3 shows the production from crops and pasture as livestock protein decreases, according to the OptoFood model (including both land use optimisation and dynamic food system modules, here minimising total ET from pasture and cropland; Figure 1). Pastures that can be used for crop production are converted first, while retaining substantial grass from non-arable rangelands still used for grazing livestock. As livestock protein decreases further, feed no longer comes from food-grade crops. Other than pasture, feed is either 1 ) a by-product of food production for oilseeds (in Figure 3, Sunflower, Groundnuts, Rapeseed, Soybean, and oilseeds in "Others"), 2) not food-grade, for the rest of the crops, or 3$)$ not edible, i.e. "crop residues". 

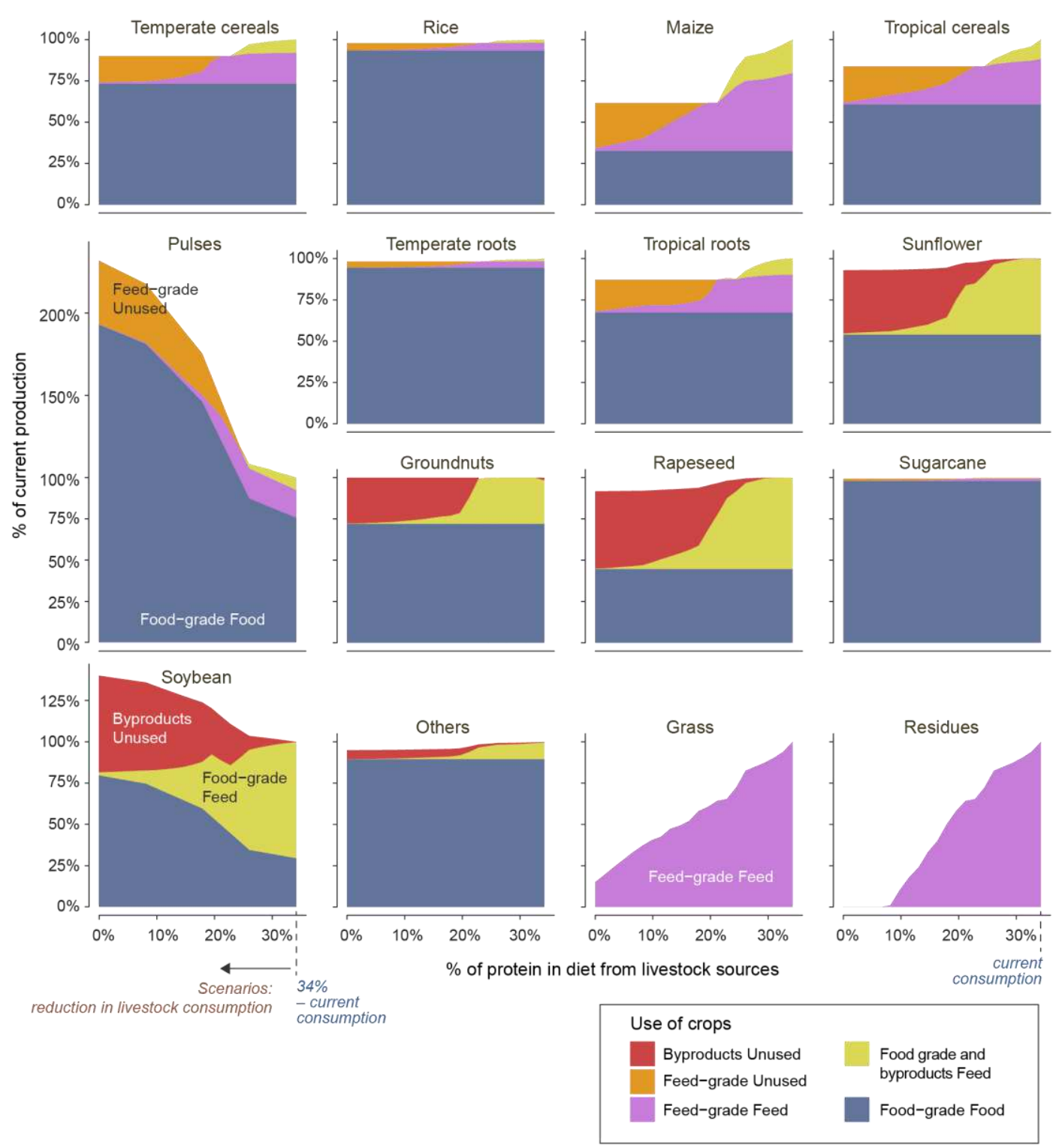

176 Figure 3: Total global crop and pasture production, when optimizing land use and livestock production systems for different levels of protein from livestock sources, minimising total evapotranspiration from cropland and pasture, with $75 \%$ of "free" grass from rangelands. 


\begin{tabular}{|c|c|}
\hline System characteristics & Effect when decreasing livestock protein \\
\hline $\begin{array}{l}\text { Should evapotranspiration of pastures count? } \\
\text { Use of part of the pasture as cropland is not feasible or } \\
\text { efficient due to terrain, soil and climate conditions. Sustainable } \\
\text { grazing may even enhance biodiversity and increase water } \\
\text { availability. }\end{array}$ & $\begin{array}{l}\text { If some portion of grass is "free", then water use actually } \\
\text { increases when replacing livestock products - some level of } \\
\text { livestock product consumption increases food } \\
\text { supply/decreases total water use }\end{array}$ \\
\hline \multicolumn{2}{|l|}{ Crop utilisation } \\
\hline $\begin{array}{l}\text { Food-feed co-production - by-products } \\
\text { Economic feasibility of certain crops depends on also utilising } \\
\text { parts of crops not used for human food }{ }^{42} \mathrm{e} . \mathrm{g} \text {. oilseeds produce } \\
\text { oil and cake, typically fed to livestock }\end{array}$ & $\begin{array}{l}\text { By-products of food production cannot be avoided, even if they } \\
\text { are no longer needed for feed. Resource use does not } \\
\text { decrease. }\end{array}$ \\
\hline $\begin{array}{l}\text { Use of non-food-grade crops } \\
\text { Crops are of variable quality, and those not meeting quality } \\
\text { requirements are often used as feed }\end{array}$ & $\begin{array}{l}\text { Production of non-food-grade crops cannot be avoided, but } \\
\text { they cannot be used for food when feed use is abandoned. }\end{array}$ \\
\hline $\begin{array}{l}\text { Crop residues } \\
\text { Usable as roughage feed, decreasing the use of grass }\end{array}$ & $\begin{array}{l}\text { Residues replace a part of roughage feed. This is a "free" } \\
\text { resource rendered unused when feed use decreases. }\end{array}$ \\
\hline
\end{tabular}

\section{Quick reduction and possible uptick in water use}

Turning now to the water use as a function of diet change, the OptoFood model allows us to test whether we can find optimum proportion of livestock-based protein consumption from a water efficiency point of view, i.e. whether water use would grow when livestock-based food approaches zero percent. This can be expected given that part of the livestock feed does not compete with human food $^{20,36}$ (see also unused by-products in Figure 3) and thus might constitute a more resource efficient protein source than growing plant-based foodstuffs to substitute the animal protein in diets. This is partly because of the land use efficiency described above, partly due to the non-competing feed sources no longer being utilised and thus appearing as losses in crop production, as described in the previous section.

Figure 4 shows the change in evapotranspiration from cropland and arable grassland use as a function of percentage of protein in the diet obtained from livestock sources, such that cropland is switched from feed to pulses and soy production while optimising cropland allocation to minimise evapotranspiration (see Supplementary Information, “MinET"). The assumption about water use of rangelands is the key. Here, we show the impact of treating it identically to other crops ( $0 \%$ 'free grass') compared to assuming that $75 \%$ of the grassland area is 'free' in terms of food water use.

There is indeed a rapid reduction in total water consumption as the percentage of livestock-based protein decreases in each scenario (Figure 4). Taking $75 \%$ free grass scenario as an example, reducing the livestock protein content in the diet by one fifth (from $34 \%$ to $27 \%$ ) decreases water use by $24 \%-$ over $79 \%$ of the maximum reduction potential. As the diet change then progresses towards even less livestock-based foods, the modelled water use does level off, but the actual size of the uptick, if any, varies depending on the assumptions regarding water allocation to different non-food feedstuffs (see Methods). The percentage of grassland assumed non-arable has the greatest effect on this. The higher the proportion of the free grass, the lower the total water use, but the shape of the curve also differs. 
consumption of some livestock products is better than none. Our results refine existing findings, obtained using the simpler common methodology that uses average water footprint, i.e. subtracting the average water volume currently needed for livestock production, and adding the average water needed for pulses and soy (dashed line in Figure 4). Our results show a significantly steeper initial reduction than estimated with this global average water efficiency method (Figure 4), but then the gain from diet change levels off after the point when livestock provides roughly $15-20 \%$ of protein in human diet (i.e. 40-55\% of reduction in animal protein intake). This does leave some scope for debate on sustainable limits for livestock product consumption.

217

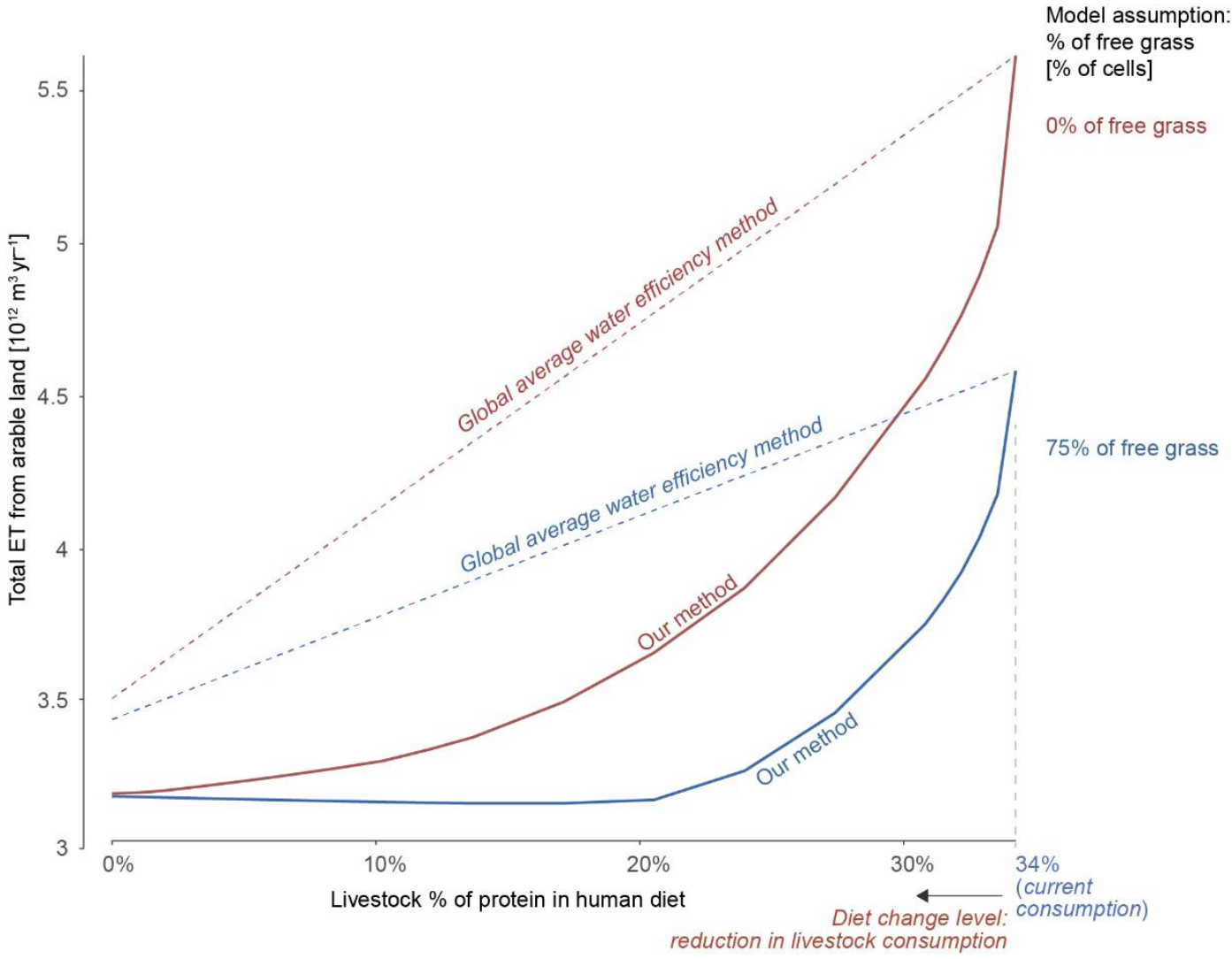

Figure 4: Evapotranspiration from arable land in two scenarios. \% of free grass denotes the percentage of cells with ET closest to natural that are considered non-arable and not contributing to the total ET. The solid curves ("Our method") denote water use with optimised cropland and livestock with different amounts of pasture considered rangeland (not contributing to total ET). Dotted lines ("Global average water efficiency method") denote the effects of the same diet change calculated using the baseline global average water efficiency for livestock-based and replacement plant-based protein.

\section{Comparing optimisation objectives}

226 There are also other potentially important goals when reducing meat consumption than minimising absolute water use as done in the analysis above (i.e. here evapotranspiration, see Figure 4). While saving water anywhere in the world improves water productivity and potentially food security ${ }^{43}$, it is also easy to consider that a drop saved is worth more where water is scarce than where it is abundant, or that we should be trying to minimise change from natural conditions to avoid detrimental effects on 
231 the hydrological cycle. Figure 5 shows the change in three objectives, and their spatial distribution:

232 evapotranspiration, water stress, and change in evapotranspiration from natural conditions.

233 When minimising the total water use when $20 \%$ of livestock protein is replaced by pulses and soy, the 234 water use does reduce considerably in some of the water scarce areas (Figure 5A-C), particularly in 235 North Africa, India and Middle East. If we would instead optimise the allocation of crops that substitute 236 the lost $20 \%$ of livestock protein so that water stress ${ }^{44}$ would be minimised (see "MinStress" in

237 Supplementary Information), the effect is even more prominent than when minimising water use 238 directly (Figure 5D-F). Global average stress, across all basins, decreases rapidly by removing production 239 from high stress areas, with many basins rapidly dropping below the commonly used threshold of $20 \%$ 240 use-to-availability to be classified as not stressed ${ }^{44}$. Mapping water stress confirms that with one-fifth 241 reduction in protein from livestock, water stress due to agriculture is eliminated in most basins by a 242 combination of diet change and associated redistribution of production. Out of 425 originally stressed 243 basins, stress remains in 46 . The agricultural land affected by stress is reduced by $85 \%$.

244 With the third objective function we wanted to explore how the $20 \%$ reduction in livestock protein 245 would bring us closer to natural evapotranspiration conditions (see MinDiff in Supplementary 246 Information). This objective reflects the idea that minimising evapotranspiration is not always 247 considered beneficial, e.g. bare ground often has lower evapotranspiration than natural vegetation.

248 Accordingly, minimising change from natural conditions, be it negative or positive, may be preferable to 249 minimising evaporation. While the shape of the curve is again similar (Figure 5G), the spatial change in 250 the objective (Figure $5 \mathrm{H}-\mathrm{I}$ ) and the agricultural land allocation are markedly different from that when 251 minimising evapotranspiration (see Supplementary Information Figure S1), this time following the 252 regional differences between agricultural and natural ET (Figure 5G, and for comparison, Bosmans et 253 al. $\left.{ }^{45}\right)$. 

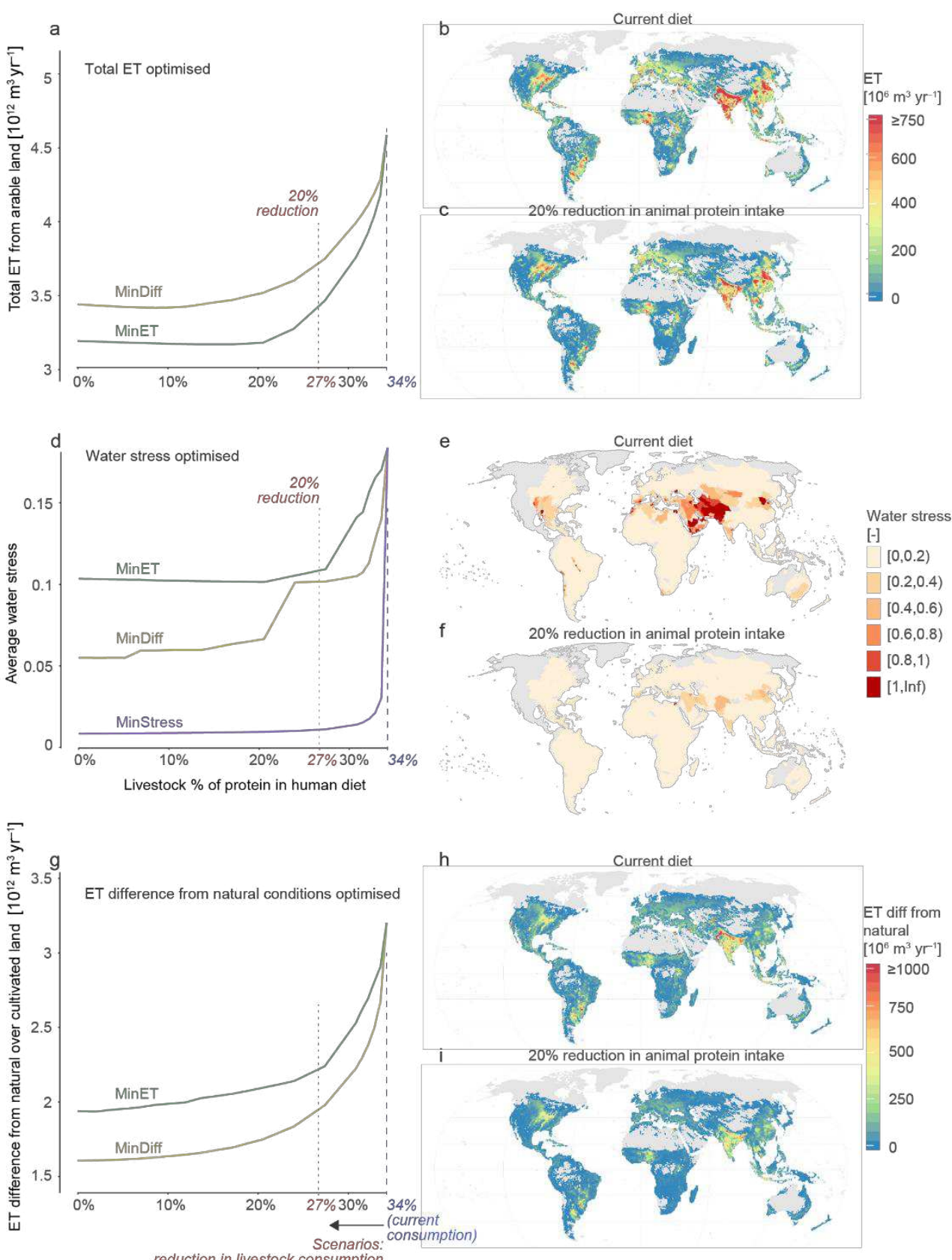

Figure 5: Optimisation objective aggregated globally and mapped spatially with alternative objective functions: (A-C) minimising evapotranspiration, MinET, (D-F) minimising average water stress, MinStress, and (G-I) deviation from natural evapotranspiration, MinDiff. Average water stress corresponds to the percentage of evaporative water consumption for irrigated agriculture relative to availability, averaged across all basins. Water stress is not sensitive to changes in rainfed agriculture, and ET and deviation from natural ET are therefore not shown for that objective.

\section{Discussion}

While existing studies have tackled the issue of sustainable limits on livestock product consumption by considering non-food inputs to animal production ${ }^{20,36,46}$, we evaluated the effect of diet change on water use by dynamically modelling where crops are grown and what feed is used. Our findings suggest 
that small reductions in meat consumption can potentially have considerably larger impact than previously estimated ${ }^{4,12,16}$, if the food system change is optimised as done here for the time. Our results, nevertheless, do still suggest that it is possible that some amount of livestock production does not compete with human food, in agreement with Davis and $D^{\prime}$ Odorico ${ }^{20}$ and Mottet et al. ${ }^{21}$. However, we do not rule out that a diet without meat uses still less water, as it depends on assumptions about water

271 use in rangelands in particular (Figure 4).

272 The decreases in water use described here are likely to be robust given that they rely on the principle of

273 diminishing returns. For example, preserving calories vs. protein provides similar results (see Methods

274 and Supplementary Fig. S2). However, the precise numbers are likely to change as methods improve.

275 Estimates of resource use and productivity could be improved with data allowing increased detail in how management practices are represented, including water management, multi-cropping, and spatially explicit modelling of livestock. As we are dealing with large system-wide changes, it is difficult to anticipate future structure of the economy, but it would still be useful to further include possible future scenarios relating to improved agricultural management and its incentives, trade, and climate change. Examining resource use and scarcity across seasons and years would also help understand the role of animals as a risk management strategy, and interactions with aquaculture, seafood and other agricultural uses should also be integrated ${ }^{3}$. Water quality impacts of food production also need to be included in future analyses.

284 To conclude, we show that a moderate change towards consuming less livestock-based foodstuffs can be efficient in saving water while moving further away from livestock products shows less additional benefits, from water saving perspective. However, realistic scenarios show at most a small increase in water consumption even when farmed animal foodstuffs are completely abandoned. Our results thus indicate that preserving many of the benefits offered by livestock is possible while at the same time substantially reducing existing overuse of water resources. These benefits include utilising animal draft power ${ }^{47,48}$, nutritionally ${ }^{49}$ and culturally desirable use of animal-based foods, emergency supply strategies based on integrated production of crops and livestock $\mathrm{k}^{50}$, and providing an economically valuable use in years with surplus or poor quality crop production. Our findings thus show that changes 293 in diet do not need to radical, which may help in initiating change, when the response to the changes is 294 done wisely. It is thus not an all or nothing proposition. 


\section{Methods and data}

Here we present an outline of the data used and the functionality of the Aalto OptoFood model. See Supplementary Information for a more detailed description with equations.

\section{Scenario design}

In order to capture the important dynamics in the global human food system, the OptoFood model (see Figure 1) combines food supply, water availability, and agricultural crop and livestock data with a linear programming optimisation model that finds the optimal land use patterns for crops (at 0.5 degree grid resolution) and optimal spatial distribution of livestock production (in 10 world regions and 3 production systems) to fulfil a given food demand. In order to analyse the effects of different levels of diet change, the optimisation model is run for a range of animal protein shares (from current to none). These diet changes are modelled by the Dynamic food system module adjusting current food demand, gradually replacing livestock-based foods with an amount of pulses and soy with equal protein content, similar to Vanham et $\mathrm{al}^{16}$. Separate model runs are conducted with different levels of non-arable pasture (see Results: "Effect of diet change on water use") and different optimisation objectives (see Results: "Effect of optimisation objective"), which are key factors influencing the results, as well as alternative diet changes (see Supplementary Figure S2).

The model is calibrated to current conditions (including diet and agricultural practices) in a multi stage process, accounting for discrepancies between data sources (for full description, see "Model calibration" in Supplementary Information). The Agricultural land module obtains estimates of crop yields, evapotranspiration and current harvested areas from the LPJmL model ${ }^{51}$ (see "Crop data" below), which is calibrated to FAOSTAT yields ${ }^{52}$ (see Supplementary Figure S3). Food demand is taken from FAO Food Balance Sheets, adjusted to match the LPJmL production. Feed use parameters and current livestock production systems for the Dynamic food system module are adopted from existing sources, and the composition of concentrate feed is calibrated to match LPJmL production and FAO demand ${ }^{53-55}$.

Restrictions are placed on the optimisation model to obtain more realistic land use patterns (Agricultural land module), notably regarding permitted land use, water availability, and feed (see Supplementary Table S2). Nevertheless, some model assumptions are subject to high uncertainty, but have a remarkable effect on the system. As such, the scenarios should be considered representative of different possible behaviours of the system rather than absolute predictions of water use.

\section{Model structure: Optimisation problem definition}

A summary of the optimisation problem and data in the OptoFood model is provided in Supplementary Table S4.

Three different criteria can be optimised in the Land use optimisation module (for full definition, see "Objective functions" in Supplementary Information). First, crop water consumption can be minimised to find the lower bound of evaporative water use in food production. This objective is referred to as MinET. Second, average water stress across basins can be minimised by objective MinStress, weighting blue water evapotranspiration by water availability. Third, as an indicator of deviation from the natural state due to the land conversion, it is possible to minimise the difference between the evapotranspiration (ET) of natural vegetation and that of the optimised agricultural land use. We refer to this objective as MinDiff. 
The decision variables in the linear programming model are i) harvested areas within 0.5 degree grid cells for each combination of crop functional types (CFTs) and available irrigation types ${ }^{56}$ (none, flood, sprinkler, drip - each available only on areas already installed), as represented by the LPJmL model, and ii) production amounts of each of six livestock products (see Supplementary Figure S4 A-F). Harvested areas are used to calculate production (area multiplied by crop yields [t/ha]) to meet crop demand, evaporative water use (area multiplied by modelled evapotranspiration [ $\mathrm{mm}]$ during the growing period) and irrigation water use (area multiplied by modelled net water withdrawals [mm]). The livestock production is used to calculate crop feed demand.

\section{Crop data}

We use LPJmL version $3^{51}$ as a data source for yields, crop residue (unutilised crop biomass usually left on the field), evapotranspiration and irrigation requirements during the reference year (2000), driven by historical climate data CRU TS3.1057 and averaged during the period 1975-2005. LPJmL assigns all agricultural crops used into 12 explicit crop functional types (CFTs, listed in Supplementary Table S1). A $13^{\text {th }}$ CFT contains "other" crops not explicitly represented elsewhere, simulated as grasslands, and a $14^{\text {th }}$ CFT is defined for pasture. Pasture (CFT 14) is treated differently from other crops. First, the share of CFT 13 (other crops), that is not covered by the FBS, is moved to CFT 14 and considered roughage feed. Second, because LPJmL's CFT 14 is not calibrated, the yield and evapotranspiration of CFT 14 are regionally reduced to match the share of roughage consumed by livestock according to the feed conversion ratios. This is based on the assumption that the livestock biomass utilisation ratio is preserved when livestock production is reduced. Third, depending on the scenario, a percentage of nonirrigated grass production is considered to occur on non-arable rangeland; grass production from these cells does not contribute to the total evaporative water consumption of food production (see "Discussion and conclusions" for rationale). This rangeland is chosen by a fixed percentage of cells where grass evapotranspiration is closest to natural vegetation ET (see Figure 1).

\section{Optimisation constraints}

\section{Demand constraints}

The total crop demand consists of three components: extrinsic human food supply varying between diet change levels, static supply for other uses, and intrinsic livestock feed demand. Livestock demand is externally specified through diet change, and also includes small amounts of static supply for other uses. Crop production is required to be at least as large as the sum of direct human crop demand including losses and feed consumption, with livestock production at least equal to direct human livestock demand (for equations, see "Demand constraints" in Supplementary Information). Production of each of the CFTs is determined for each cell as the product of the harvested area and modelled crop yield. The demand is global - we assume free trade for both the crops for human consumption and crop feed for livestock. Current trade arrangements cannot easily be assumed to stay constant in the presence of large demand changes.

The extrinsic crop demand is the sum of human food and all other crop uses. We consider the other uses constant, but the food demand varies according to the diet change level. The current average human diet for each country is derived from FAOSTAT Food Balance Sheets ${ }^{55}$. Population data is based on HYDE database version $3.2^{58}$. 
For each diet change level, a given percentage of livestock products is replaced with pulses and soy (see Supplementary Table S3), keeping the protein content constant, which then means there is some variation in energy content (4\% decrease from $2157 \mathrm{kcal} / \mathrm{cap} / \mathrm{d}$ to $2065 \mathrm{kcal} / \mathrm{cap} / \mathrm{d}$ in the included food items, including food waste). Both for health reasons and to conserve food production resources, for many people it would be possible and beneficial to replace only a part of the livestock protein, i.e. decrease the total protein in their diets. The effect of decreasing total protein on food water use is almost linear, and matching dietary energy instead of protein has a very small effect on evapotranspiration (see Figure S2 in the Supplement). To highlight the effects of different food sources rather than other changes to the diet, we kept the amount of protein constant in our main scenarios. The ratios between livestock products are also kept constant globally to avoid introducing additional dynamics. The ratio between pulses and soy is also preserved to acknowledge country-level food preferences.

For oilseed crops, we differentiate between the portion of the crop resulting in oil vs cake during the processing stage. The ratio of production of oil and cake is treated as constant with values derived from FAOSTAT Commodity Balances ${ }^{55}$ (see Supplementary Table S1). In the baseline situation all the current oil production is for human consumption and most of the cake goes to feed use (see "Model calibration" in Supplementary Information for details). The cake is, however, protein rich. As part of the diet change, the whole soybean crop is therefore used as food - with no distinction between oil and cake.

The fraction of crop demand for human food must be satisfied by crops fulfilling safety and quality requirements set for food. These regulations vary by country, and availability of statistics about quality is limited. Crops not fulfilling food grade requirements can often be used as feed. A fixed percentage of crop production is assumed to be feed-only quality globally. In absence of reliable global crop quality data, $70 \%$ of the amount of each CFT currently used as feed is assumed feed-only quality, except in the case of oilseeds, where the oil fraction is assumed fully food quality. How well the average modelled feed composition fits with the human food demand structure determines how much of the substandard quality crop production can enter the food supply chain through the livestock sector.

The relationships between livestock production and feed requirements are derived from the appendix tables of UNESCO Value of Water series Report $48^{53}$. The crop composition of concentrate feed is derived from FAOSTAT Commodity balances ${ }^{55}$ (part of the Food Balance database). In optimisation, production systems are permitted to use either regional or global feed composition for concentrate feed, consistent with our free trade assumptions.

The livestock crop feed requirements are handled by the demand constraints, but a large percentage of feed consists of grass and other roughage. The roughage comes from the yield of CFT 14, and additionally it can consist of a limited amount of crop residues of CFTs 1-12. The crop residues are limited to a maximum of $40 \%$ of the total roughage to avoid large changes in feed composition. As roughage is relatively inexpensive, we assume that it cannot be effectively traded across region boundaries. In practice, it is largely utilised directly as pasture or harvested and stored as silage, but still consumed relatively close to the site of production.

\section{Harvestable area}

The potentially harvestable area is derived from the current land use pattern as the sum of the harvested areas of all crops. It is further divided into four categories depending on irrigation equipment 
- rainfed, flood irrigated, sprinkler irrigated or drip irrigated land ${ }^{56}$. Rainfed cropland is excluded if it is unsuitable according to FAO GAEZ Suitability Indices ${ }^{59}$. Within a raster cell, the harvested area of all crops must fit within the harvestable area and the irrigated growing areas must not exceed the area equipped for the corresponding irrigation type, i.e. neither agricultural land area nor irrigated area is allowed to expand. This is possible within our analysis because the emphasis is on utilising existing agricultural land as efficiently as possible in terms of water (objectives MinET and MinStress) or in a way that is hydrologically as close to natural as possible (objective MinDiff). Diet change reducing animal content in diets tends to decrease rather than increase land and water use, and as long as population or diet requirements per person are not increasing, new agricultural land is not needed. Expansion scenarios could easily be introduced using alternative land use patterns.

\section{Constraints on spatial re-allocation of production: "stickiness"}

We assume that completely reallocating crop production according to the per-crop productivity would be infeasible due to extensive changes in agricultural practices and machinery. Thus, relocation of preserved production is prevented by "stickiness" constraints. This means that the harvested area for a crop with increasing demand (later referred to as an "increasing crop") can only increase or stay constant in any cell, and the harvested area for a crop with decreasing demand ("decreasing crop") can only decrease or remain unchanged in any cell, making the current and unchanging production amount "stick" to its location. The increasing production for example for oilseeds can thus only occupy areas freed from decreasing production of crops and grass used for livestock feed. Reallocation can occur wherever suitable cropland becomes available, allowing trade patterns to change.

Production of meat, milk and eggs are each split into grazing, mixed, and industrial production systems. These are defined according to Mekonnen and Hoekstra ${ }^{53}$ to be compatible with their feed conversion efficiency data. Similarly to the stickiness constraints used with cropland reallocation, each livestock product within each region and each production system can only decrease as a result of the diet change, i.e. no production can be moved from one area or system to another.

\section{Water availability}

Irrigation in each grid cell is limited by the current net withdrawals (irrigation water withdrawals irrigation return flows), as modelled by the LPJmL ILIM model configuration ${ }^{60}$. The total net withdrawals per basin (after return flows) are not allowed to increase. Decreases in irrigation may be transferred to downstream cells within a basin. The drainage directions for raster cells are determined by the STN-30p simulated topological network ${ }^{61}$, as used by LPJmL in the ILIM simulation.

\section{Data availability statement}

The data that support the findings of this study are available from the corresponding author upon reasonable request.

Code availability statement

Software code is proprietary for the time being. 


\section{Acknowledgements}

The authors received financial support from Maa- ja vesitekniikan tuki ry, Academy of Finland funded project WASCO (grant no. 305471), Emil Aaltonen Foundation funded project "eat-less-water", Strategic Research Council (SRC) through project 'From Failand to Winland', and European Research Council (ERC) under the European Union's Horizon 2020 research and innovation programme (grant agreement No. 819202)

\section{References}

1. Godfray, H. C. J. et al. Food security: the challenge of feeding 9 billion people. Science $327,812-818$ (2010).

2. Tilman, D., Balzer, C., Hill, J. \& Befort, B. L. Global food demand and the sustainable intensification of agriculture. Proc. Natl. Acad. Sci. 108, 20260-20264 (2011).

3. Kummu, M. et al. Bringing it all together: linking measures to secure nations' food supply. Curr. Opin. Environ. Sustain. 29, 98-117 (2017).

4. Gerten, D. et al. Feeding ten billion people is possible within four terrestrial planetary boundaries. Nat. Sustain. 3, 200-208 (2020).

5. Fischer, T., Byerlee, D. \& Edmeades, G. Crop yields and global food security: will yield increase continue to feed the world? (ACIAR, Australian Centre for International Agricultural Research, 2014).

6. Licker, R. et al. Mind the gap: how do climate and agricultural management explain the 'yield gap' of croplands around the world? Glob. Ecol. Biogeogr. 19, 769-782 (2010).

7. Mauser, W. et al. Global biomass production potentials exceed expected future demand without the need for cropland expansion. Nat. Commun. 6, 8946 (2015).

8. Davis, K. F., Rulli, M. C., Seveso, A. \& D'Odorico, P. Increased food production and reduced water use through optimized crop distribution. Nat. Geosci. 10, 919 (2017). 
9. Alexander, P. et al. Losses, inefficiencies and waste in the global food system. Agric. Syst. 153, 190200 (2017).

10. Kummu, M. et al. Lost food, wasted resources: global food supply chain losses and their impacts on freshwater, cropland, and fertiliser use. Sci. Total Environ. 438, 477-489 (2012).

11. Finucane, M. M. et al. National, regional, and global trends in body-mass index since 1980: systematic analysis of health examination surveys and epidemiological studies with 960 countryyears and 9.1 million participants. The Lancet 377, 557-567 (2011).

12. Jalava, M., Kummu, M., Porkka, M., Siebert, S. \& Varis, O. Diet change-a solution to reduce water use? Environ. Res. Lett. 9, 074016 (2014).

13. Poore, J. \& Nemecek, T. Reducing food's environmental impacts through producers and consumers. Science 360, 987-992 (2018).

14. Vanham, D., Comero, S., Gawlik, B. M. \& Bidoglio, G. The water footprint of different diets within European sub-national geographical entities. Nat. Sustain. 1, 518 (2018).

15. Gordon, L. J. et al. Rewiring food systems to enhance human health and biosphere stewardship. Environ. Res. Lett. 12, 100201 (2017).

16. Vanham, D., Hoekstra, A. Y. \& Bidoglio, G. Potential water saving through changes in European diets. Environ. Int. 61, 45-56 (2013).

17. Gephart, J. A. et al. The environmental cost of subsistence: Optimizing diets to minimize footprints. Sci. Total Environ. 553, 120-127 (2016).

18. Ran, Y., van Middelaar, C. E., Lannerstad, M., Herrero, M. \& de Boer, I. J. M. Freshwater use in livestock production -To be used for food crops or livestock feed? Agric. Syst. 155, 1-8 (2017).

19. Aleksandrowicz, L., Green, R., Joy, E. J. M., Smith, P. \& Haines, A. The Impacts of Dietary Change on Greenhouse Gas Emissions, Land Use, Water Use, and Health: A Systematic Review. PLOS ONE 11, e0165797 (2016). 
20. Davis, K. F. \& D’Odorico, P. Livestock intensification and the influence of dietary change: A calorie504 based assessment of competition for crop production. Sci. Total Environ. 538, 817-823 (2015).

21. Mottet, A. et al. Livestock: On our plates or eating at our table? A new analysis of the feed/food debate. Glob. Food Secur. 14, 1-8 (2017).

507 22. Sandström, V. et al. Untapped power of food system by-products to increase global food supply 508 PREPRINT v1. (2021) doi:10.21203/rs.3.rs-990009/v1.

23. Godde, C. M., Garnett, T., Thornton, P. K., Ash, A. J. \& Herrero, M. Grazing systems expansion and intensification: Drivers, dynamics, and trade-offs. Glob. Food Secur. 16, 93-105 (2018).

24. Heggenes, J. et al. Herbivore grazing-or trampling? Trampling effects by a large ungulate in cold high-latitude ecosystems. Ecol. Evol. 7, 6423-6431 (2017).

25. Ran, Y., Lannerstad, M., Herrero, M., Van Middelaar, C. E. \& De Boer, I. J. M. Assessing water resource use in livestock production: A review of methods. Livest. Sci. 187, 68-79 (2016).

26. Delzeit, R., Klepper, G., Zabel, F. \& Mauser, W. Global economic-biophysical assessment of midterm scenarios for agricultural markets-biofuel policies, dietary patterns, cropland expansion, and productivity growth. Environ. Res. Lett. 13, 025003 (2018).

27. Weindl, I. et al. Livestock in a changing climate: production system transitions as an adaptation strategy for agriculture. Environ. Res. Lett. 10, 094021 (2015).

28. Popp, A., Lotze-Campen, H. \& Bodirsky, B. Food consumption, diet shifts and associated non-CO2 greenhouse gases from agricultural production. Glob. Environ. Change 20, 451-462 (2010). 2696 (2020).

30. Yang, H., Pfister, S. \& Bhaduri, A. Accounting for a scarce resource: virtual water and water footprint in the global water system. Curr. Opin. Environ. Sustain. 5, 599-606 (2013). 
31. Karlsson, J. O. \& Röös, E. Resource-efficient use of land and animals-Environmental impacts of food systems based on organic cropping and avoided food-feed competition. Land Use Policy 85, 63-72 (2019).

32. Samireddypalle., A. et al. Embracing whole plant optimization of rice and wheat to meet the growing demand for food and feed. Field Crops Res. 244, 107634 (2019).

33. Muscat, A., de Olde, E. M., de Boer, I. J. M. \& Ripoll-Bosch, R. The battle for biomass: A systematic review of food-feed-fuel competition. Glob. Food Secur. 25, 100330 (2020).

34. Brambilla, G. \& Filippis, S. D. Trends in animal feed composition and the possible consequences on residue tests. Anal. Chim. Acta 529, 7-13 (2005).

35. National Academies of Sciences, E., and Medicine. Nutrient Requirements of Beef Cattle: Eighth Revised Edition. (The National Academies Press, 2016). doi:10.17226/19014.

36. Röös, E., Patel, M., Spångberg, J., Carlsson, G. \& Rydhmer, L. Limiting livestock production to pasture and by-products in a search for sustainable diets. Food Policy 58, 1-13 (2016).

37. Alkemade, R., Reid, R. S., van den Berg, M., de Leeuw, J. \& Jeuken, M. Assessing the impacts of livestock production on biodiversity in rangeland ecosystems. Proc. Natl. Acad. Sci. U. S. A. 110, 20900-20905 (2013).

38. Török, P., Hölzel, N., van Diggelen, R. \& Tischew, S. Grazing in European open landscapes: How to reconcile sustainable land management and biodiversity conservation? Agric. Ecosyst. Environ. 234, 1-4 (2016).

39. van Klink, R. et al. Effects of grazing management on biodiversity across trophic levels-The importance of livestock species and stocking density in salt marshes. Agric. Ecosyst. Environ. 235, 329-339 (2016).

40. Matson, P. A. \& Vitousek, P. M. Agricultural Intensification: Will Land Spared from Farming be Land Spared for Nature? Conserv. Biol. 20, 709-710 (2006). 
41. FAO. BIOFUEL CO-PRODUCTS AS LIVESTOCK FEED: Opportunities and challenges. (FAO - Food and Agriculture Organization of the United Nations, Rome, 2012).

42. FAO. PROTEIN SOURCES FOR THE ANIMAL FEED INDUSTRY. (2004).

43. Hoekstra, A. Y. \& Mekonnen, M. M. The water footprint of humanity. Proc. Natl. Acad. Sci. (2012) doi:10.1073/pnas.1109936109.

44. Kummu, M. et al. The world's road to water scarcity: shortage and stress in the 20th century and pathways towards sustainability. Sci. Rep. 6, 38495 (2016).

45. Bosmans, J. H. C., Beek, L. P. H. van, Sutanudjaja, E. H. \& Bierkens, M. F. P. Hydrological impacts of global land cover change and human water use. Hydrol. Earth Syst. Sci. 21, 5603-5626 (2017).

46. Smith, J. et al. Beyond milk, meat, and eggs: Role of livestock in food and nutrition security. Anim. Front. 3, 6-13 (2013).

47. Baudron, F., Jaleta, M., Okitoi, O. \& Tegegn, A. Conservation agriculture in African mixed croplivestock systems: Expanding the niche. Agric. Ecosyst. Environ. 187, 171-182 (2014).

48. Zhou, X., Ma, W. \& Li, G. Draft Animals, Farm Machines and Sustainable Agricultural Production: Insight from China. Sustainability 10, 3015 (2018).

49. Godber, O. F. \& Wall, R. Livestock and food security: vulnerability to population growth and climate change. Glob. Change Biol. 20, 3092-3102 (2014).

50. Kananen, I. Suomen huoltovarmuus - Riittääkö energia ja ruoka, toimiiko tiedonkulku? (Docendo, 2015).

51. Bondeau, A. et al. Modelling the role of agriculture for the 20th century global terrestrial carbon balance. Glob. Change Biol. 13, 679-706 (2007).

52. Fader, M., Rost, S., Müller, C., Bondeau, A. \& Gerten, D. Virtual water content of temperate cereals and maize: Present and potential future patterns. J. Hydrol. 384, 218-231 (2010). 
573 53. Mekonnen, M. M. \& Hoekstra, A. Y. The green, blue and grey water footprint of farm animals and $574 \quad$ animal products. (2010).

575 54. Sere, C. \& Steinfeld, H. LEAD Digital library - World livestock production systems: current status, 576 issues and trends. http://www.fao.org/3/W0027E/W0027E00.htm (1996).

577 55. FAO. FAOSTAT - FAO database for food and agriculture. Rome: Food and agriculture Organisation of $578 \quad$ United Nations (FAO) http://faostat3.fao.org/home/index.html (2016).

579 56. Portmann, F. T., Siebert, S. \& Döll, P. MIRCA2000-Global monthly irrigated and rainfed crop areas 580 around the year 2000: A new high-resolution data set for agricultural and hydrological modeling. $581 \quad$ Glob. Biogeochem. Cycles 24, (2010).

582 57. Harris, I., Jones, P. D., Osborn, T. J. \& Lister, D. H. Updated high-resolution grids of monthly climatic observations - the CRU TS3.10 Dataset. Int. J. Climatol. 34, 623-642 (2014).

584 58. Goldewijk, K. Anthropogenic land-use estimates for the Holocene; HYDE 3.2. (2017) doi:10.17026/dans-25g-gez3.

586

59. Fischer, G. et al. Global Agro-Ecological Zones (GAEZ v3.0). (IIASA, 2016).

587 60. Rost, S. et al. Agricultural green and blue water consumption and its influence on the global water 588 system. Water Resour. Res. 44, n/a-n/a (2008).

61. Vörösmarty, C. J., Fekete, B. M., Meybeck, M. \& Lammers, R. B. Global system of rivers: Its role in organizing continental land mass and defining land-to-ocean linkages. Glob. Biogeochem. Cycles 14, 599-621 (2000). 


\section{Supplementary Files}

This is a list of supplementary files associated with this preprint. Click to download.

- Jalavasupplement.pdf 